\title{
The Proceedings of the Third International and Interdisciplinary Conference about the Tungus
}

\author{
NIKOLAI S. GONCHAROV
}

\begin{abstract}
The Third International and Interdisciplinary Conference about the Tungus "Social Interactions, Languages, Landscapes in Siberia and China (Evenki, Evens, Orochons and Other Groups)" was organized by the Amur Region State University (Blagoveshchensk, Russia) and other coorganizers on June 14-16, 2019. The conference was devoted to the study of Tungus peoples from different standpoints and scientific/theoretical approaches. It demonstrated the vivid interest of researchers from many countries all over the world to the discussed topics. One of the main distinctions of this particular event was the resourceful and multifaceted intercommunication between scholars, indigenous people, and local authorities.
\end{abstract}

Keywords: Blagoveshchensk, China, conference participation, conferences, Siberia, Tungus

he Third International and Interdisciplinary Conference about the Tungus, titled "Social Interactions, Languages, Landscapes in Siberia and China (Evenki, Evens, Orochons and Other Groups)" was held in Blagoveshchensk, Russia on June 14-16, 2019. The main organizer of the event was Amur Region State University (Blagoveshchensk), alongside multiple coorganizers, including the Peter the Great Museum of Anthropology and Ethnography (Kunstkamera) RAS Russian Academy of Sciences (St. Petersburg), CEARC (Paris), Vilnius University, and the Academia Sinica. The two previous conferences on Tungus studies were held outside the Russian Federation - in France (2013) and in Lithuania (2015). The main topic of this iteration of the conference was to be social relations and languages; however, the themes actually discussed at the meeting turned out to be wider than declared. 
Sessions took place over the course of two days, and the geographical origins of participants were quite broad-Canada, United States, France, Great Britain, Norway, Finland, Lithuania, Japan, and an especially large delegation from China, whose territory begins on the opposite bank of the Amur River from Blagoveshchensk. The main conference agenda was identified as the issues of genesis, evolution, and historical transformations of the Manchu-Tungus groups and this direction led to the involvement of specialists from various fields and disciplines into the study of more or less one main objective.

The content of the plenary session occurred in three separate reports. In the first of them, A. P. Zabiyako provided an analysis of the early petroglyphic texts of the Jurchen people found on the rock paintings on the Arkhara River (Amur region). It allowed scholars to make clarifications in the classification of the Jurchen language. Zabiyako also introduced new materials discovered during archaeological excavations in northeast China, represented by the mountain fortifications of the Jurchen. This data made it possible to compare both written and material sources about the early population of the modern RussianChinese border area of the Amur River basin. In the second report, D. Brandišauskas revealed some aspects of the relationship between Evenki reindeer herders and wolves from a historical perspective. The researcher showed how forms of this interaction were changed when the human-animal relationship status of "neighbors" was transformed into "enemies." Brandišauskas noted that in many ways the perception of wolves as dangerous predators was formed in the Evenki society from the outside; in an "authentic" Evenki environment wolves were traditionally perceived as integral and acceptable neighbors. Long-term coexistence with wolves led to the development of an understanding between animals and humans. Alternatively, in the case of the policy of extermination of the animals, there was not enough time to form "good-neighborliness" between wolves and Evenki. Finally, the plenary session concluded with a presentation made by V. N. Davydov. The researcher analyzed how the state influenced the mode of life of Evenki in Northern Baikal. He showed that innovations that penetrated the culture of the community from the state were often not synonymous with the complete transformation of the group's life. Innovations and traditions could coexist in parallel. Moreover, innovations could be perceived and domesticated precisely within the framework of the existing sociocultural structure without affecting it critically.

The session "In Memory of S. M. Shirokogoroff ..." incorporated a number of main thematic strands. In the first part (presented by 
A. A. Sirina, V. N. Davydov, and A. M. Pevnov), the historical, ethnographic, and linguistic aspects of Tungus studies were analyzed in light of the issues researchers faced during the period of preparing for the publication of Shirokogoroff's book "Social Organization of the Northern Tungus" (in Russian). Further, there was a discussion of Manchu-Tungus shamanism (presentation by T. Yu. Sem), an analysis of field materials collected among the peoples of northeast China (conducted by the Russian and Chinese researchers N. Ia. Bulatova, H. Yufeng, and M. Shusyan) and some reflections on museum exhibits (L. I. Missonova). In the final presentation, A. Lavrillier presented materials devoted to Evenki snow typology, which allow indigenous people to predict weather conditions over a long period. The researcher noted that the traditional knowledge of snow can be used in multiple spheres. First, it can be used within the community for the successful implementation of the economic activities of the group; secondly, it is possible to apply this knowledge to climate change problems in the natural sciences. Thus, local knowledge can take on global significance.

Various aspects of the culture and social dynamics of the population of the Amur river basin were covered within the session "History and Current Status of Tungus Ethnic Groups in the Northeastern China," which was formed almost entirely by Chinese researchers. While the title of the session evokes some of the material of the previous session, it differed in content. It is possible to distinguish several large thematic blocks within the session: (a) plots of traditional nature management and law enforcement in this area (these presentations were prepared by a research group led by G. Fondahl based on field materials from the Republic of Sakha-Yakutiia); (b) topics concerning ethnogenesis and problems of ethnic contacts (on the example of Evenki, Evens and Ainu peoples); and (c) historiographic materials from the North Baikal branch of the Tungus expedition in 1927-1928. There were also reports devoted to gender issues, spatial practices, and so on. Overall the session presented a balance of historical immersion and contemporary concerns.

Many participants introduced issues related to Tungus linguistics. These presentations analyzed theoretical and applied aspects of lexicography, word formation, and toponymy. Attention was paid not only to the theoretical features; the conference also became an important step toward the ongoing maintenance and development of the ManchuTungus languages. O. N. Morozova and V. S. Gibalin presented the project "Sino-Orochon-Russian Dictionary," and S. V. Androsova spoke about "The creation of an automatic transcriptor for the eastern dialect of the Evenki language." At the round table "The Problem of the Con- 
servation of Endangered Languages ..." the participants also discussed the current state of the Manchu-Tungus languages in Russia and China and considered strategies for their effective studying, development, and teaching. Thematically complementary were sessions on folklore and fiction in Tungusic and other languages.

An important trait of the conference was that it was actively attended by representatives of the indigenous Tungus peoples, whose culture, history, and so on were discussed in numerous presentations. They also formed the session "Sociocultural situation and the environment in the regions of compact residence of the Tungus communities: an outward glance," where indigenous people from Taimyr, Verkhoyansk, Kamchatka, the southern parts of the Russian Far East, and other regions gave presentations. These representatives explained their thoughts on oft-debated issues such as traditional nature management, the preservation of languages and rituals from their specific point of view. The overarching idea was the need for uniting efforts to find solutions to preserve and develop indigenous culture and the natural environment at the present time.

The organizers of the conference sought to achieve the same outcomes as discussed above in their discussions on reindeer husbandry and language. They also held training for the Evenk youth titled "Actualization of Ethnic and Civic Identity." Within the framework of these events, district heads, officials from the education department of the Amur region, representatives of the Ministry of Foreign Affairs of the Russian Federation, and officials from the Chinese side could participate in the proceedings. Thus, the existing problems and development strategies of various spheres of Tungus peoples' life were heard and analyzed from different perspectives.

The Third International Interdisciplinary Tungus Conference was multifaceted not only in its research but the conditions in which it took place. As noted briefly, the Chinese side of the river is clearly visible across the Amur from its Russian bank, and vice versa. After the official part of the event, the participants crossed the river (accordingly, the state border) to the territory of a neighboring state. This interpenetration of cultures is visual, as it is manifested in Russian-language inscriptions on stores in the city of Heihe (China), and Chinese characters in the city landscape of Blagoveshchensk; it can be seen in Russian citizens crossing the border from Chin, with huge bags, and an assortment of Chinese products in the Blagoveshchensk shops. This connection remains in the memory of many who attended the conference: one of the local conference participants remarked that about ten years ago 
Russians actively traveled to China since prices there were much lower. However, the situation has changed. An increasing number of Chinese people cross the Russian border as it is cheaper to go shopping in Russia. An employee of the Amur Regional Museum of Local Lore said that the residents of Blagoveshchensk are accustomed to many Chinese products, but the Chinese people also loved "our milk, sweets," and so on, revealing an interpenetration of local tastes as well.

We can also distinguish several layers that make up the conference. First, we have the research participants who are diverse in their origins by country, city, and specifics of their research activities. Second, there are different ideological layers of the conference, such as scientific, political, and ethnographic. Third, we find the opposition of "researchers" and "nonresearchers," where the latter often means representatives of indigenous peoples and administrative persons who have the opportunity to interact in the same conditions as those who conduct research. However, in this case, we can also raise the rhetorical question: "what is the conference and how can we distinguish it from a 'nonconference' if there are no organized presentations by researchers; moreover, if the nonscientists have 'thicker descriptions' and experience of those ostensibly being described?"

This leads me to muse on what really defines a conference: a place, a time, a process or something else? After all, a person who prepares his/ her report in a hotel room before the next day's speech is as involved in the conference as those engaged in discussions with colleagues about the daily reports at the conference dinner. The conference continues. As an assumption, we say that the conference is a diffusion. It seems to us that it proceeds that not only in the audiences indicated in the program, but primarily in the heads of the assembled people, and it proceeds differently in each participant's mind. The decisions and conclusions at the conference are thus made not only-and perhaps even to a lesser extent-in a formal setting, but also in the daily activities, which are not always intentionally planned. For example, when we drove from the building of the Amur State University to the cafe by bus, there was an active discussion of the problems of the Tungus reindeer herding, and some participants put forth calls to create a Tungus organization of reindeer herders.

All of these traits present the vision of a mobile configuration, placed in a temporary framework of procedure and sessions. The inherent mobility is determined by the presence of people participating, regardless of whether they are an ethnographer or a reindeer herder. These peculiarities lead one to the question: what is the difference between ethnographer and nonethnographer? Do these categories reside in the specifics of 
knowledge, social capital, or the modes of social space configurations? I am reminded of how participants created a group in the WhatsApp messenger service devoted to the upcoming event shortly before the conference. It is worthy of note that this group persisted long after the conference, as it had become a place where one could share information about new publications, seminars, and training. Virtual-technical capabilities thus allow us to prolong the existence of configurations, largely due to the significant malleability of these technologies.

In conclusion, one more point that is related to locality. The conference was held in Blagoveshchensk, a city that occupies a particularly unique geographic position (between Russia and China, and in an area of the Far East where many Tungus peoples have long been residents). It was thanks to this location that a significant number of researchers from Eastern Siberia and representatives of indigenous peoples were able to gather. Consequently, we were also able to conduct round tables and training, followed by a trip to China and a visit to an Orochon village. Thus, while the conference was attended not only by researchers, organizers, officials, and representatives of indigenous peoples, the place itself largely determined the structure of the conference, contributed to the formation of this social configuration. It was not only a passive territory for receiving guests but a subject influencing the proceedings themselves.

\section{Acknowledgments}

This article was supported by the Russian Scientific Foundation project No 18-18-00309 "The Energy of the Arctic and Siberia: The Use of Resources in the Context of Socio-Economic and Ecological Change" (PI Dr. Vladimir N. Davydov).

\footnotetext{
Nikolai S. Goncharov is a PhD student and junior researcher at the Peter the Great Museum of Anthropology and Ethnography (Kunstkamera) of the Russian Academy of Sciences. His interests include the Arctic and Northern areas of Russia, especially the northeastern part of the Republic of Sakha (Yakutia). His research focuses on space production, perception and transformation, human-animal relations, and the specifics of food in the North. His dissertation focuses on the habitualization of space on the territory of intercultural activity in the Republic of Sakha (Yakutia).

E-mail: nikola.gon4arov@yandex.ru
} 